\title{
Predictive Factors for the Long-Term Clinical Course in Patients with Rheumatoid Arthritis Receiving Second-Line Anti- Rheumatic Drugs in Real-World Practice: An Analysis Using Disease Activity Trajectory-Based Clustering Approach
}

\author{
Bon San Koo \\ Seongho Eun \\ KAIST \\ Kichul Shin

\section{Seokchan Hong} \\ University of Ulsan College of Medicine \\ Yong-Gil Kim \\ University of Ulsan College of Medicine \\ Chang-Keun Lee \\ University of Ulsan College of Medicine

\section{Bin Yoo} \\ University of Ulsan College of Medicine \\ Ji Seon Oh ( $\sim$ doogie55@naver.com ) \\ Asan Medical Center
}

Inje University Seoul Paik Hospital, Inje University College of Medicine

Seoul Metropolitan Government-Seoul National University Hospital Boramae Medical Center

\section{Research Article}

Keywords: rheumatoid arthritis, biologics, trajectory clustering/trajectory modeling, treatment response

Posted Date: November 15th, 2021

DOI: https://doi.org/10.21203/rs.3.rs-1070383/v1

License: (c) (i) This work is licensed under a Creative Commons Attribution 4.0 International License. Read Full License 


\section{Abstract}

Background: The purpose of this study was to stratify patients with rheumatoid arthritis (RA) according to the trend of disease activity by trajectory-based clustering and to identify the predictive factors for treatment response and the switching patterns of biologics according to trajectory groups.

Methods: We analysed the data from a nationwide RA cohort from the Korean College of Rheumatology Biologics and Targeted Therapy (KOBIO) registry. Patients treated with second-line disease-modifying anti-rheumatic drugs (DMARDs) were included. Trajectory modeling for clustering was used to group the disease activity trend. The predictive factors and switching patterns of biologics for each trajectory were investigated.

Results: The trends in the disease activity of 688 RA patients were clustered into 4 groups: rapid decrease and stable disease activity (group 1, N = 319), rapid decrease followed by an increase (group 2, $N=36$ ), slow and continued decrease (group $3, \mathrm{~N}=$ 290), and no decrease in disease activity (group 4, $N=43$ ). In the multivariable analysis for predictive factors, current smoking (OR, 7.845; 95\% Cl 2.158-28.220), low hemoglobin (OR 0.694; 95\% Cl, 0.532-0.901), and high initial disease activity score according to the 28-joint assessment (DAS28) $(\mathrm{OR}, 2.397 ; 95 \% \mathrm{Cl}, 1.638-3.586)$ were significantly associated with group 4 compared with group 1. Group 1 had a higher proportion of patients who had never had switching (86.5\%) and who were initially treated with non-TNF inhibitors (44.2\%) compared with groups 2 (52.8\% and 25\%), 3 (50.3\% and 23.4\%), and 4 (25.6\% and $18.6 \%)$.

Conclusions: The trajectory-based approach was useful for clustering the disease activity in longitudinal data in patients with RA. Among the four trajectories, the group with sustained high disease activity was associated with current smoking, low hemoglobin, high initial DAS28, and frequent switching of biologics.

\section{Introduction}

Patients with rheumatoid arthritis (RA) suffer from chronic inflammatory arthritis and a variety of extra-articular symptoms. Because RA patients develop long-term disabilities and experience decreases in the quality of life, they need intensive treatment early on, such as a treat-to-target strategy [1, 2]. In treatment strategies, second-line DMARDs (disease-modifying anti-rheumatic drugs), such as biologic disease-modifying anti-rheumatic drugs (bDMARDs) or targeted synthetic disease-modifying antirheumatic drugs (tsDMARDs), are used in the treatment of RA patients who do not respond to treatment with conventional synthetic disease-modifying anti-rheumatic drugs (csDMARDs) [3-5]. However, because patients have different treatment responses for bDMARDs or tsDMARDs, selecting the drug that will show the best response in each individual patient remains a difficult issue in clinical practice. Therefore, finding the predictors for treatment response to second-line DMARDs is necessary to reduce patient suffering and the burden of medical costs $[6,7]$

Although various predictors for treatment response have been proposed thus far [8-11], most studies have evaluated the treatment response at a specific time point (eg, 3 or 6 months) without considering the changes in disease activity over time in the predictive models. However, among patients treated with bDMARDs or tsDMARDs in clinical practice, some patients show improvement in disease activity at the beginning of treatment, while others show a very slow response to treatment (ie, nonresponders) and their prescription is either stopped or switched to another drug. In addition, even if the initial response to treatment is good, some patients show aggravation of disease activity over time, and some patients do not improve disease activity even if the biological agent is maintained or switched. Therefore, it is more reasonable to evaluate the treatment response as a course of the long-term disease activity.

Trajectory-based clustering is a group-based approach that has been recently used in many studies on patients with RA [12-16]. This method can determine the clusters of individuals with a similar course of disease activity over time and identify different patterns of response to treatment. Using predictive markers that are associated with each distinct disease activity pattern can increase the efficiency of the treatment response and maintain treatment effects for a long time. 
The purpose of this study was to utilize trajectory-based clustering to group the trends of disease activity in RA patients registered in the Korean College of Rheumatology Biologics \& Targeted therapy Registry (KOBIO), and to identify predictive factors for the treatment response and switching patterns of second-line DMARDs.

\section{Materials And Methods}

\section{Study population and data collection}

This study used data from the KOBIO registry, which is a nationwide multicenter cohort in Korea that was established to evaluate the effectiveness and side effects of bDMARDs (ie, abatacept, adalimumab, etanercept, golimumab, infliximab, rituximab, and tocilizumab) and tsDMARDs (ie, tofacitinib and baricitinib) in patients with RA [17]. Patients in the registry were recruited from 38 hospitals since 2012, and their demographics, medications, comorbidities, extra-articular manifestations, disease activities, radiographic findings, and laboratory findings have been recorded by investigators from each participating hospital. From December 2012 to June 2019, a total of 2,122 patients who were treated with second-line DMARDs including bDMARDs and tsDMARDs were registered. Of them, patients who had been treated with bDMARDs or tsDMARDs before registration in the $\mathrm{KOBIO}$ registry were excluded and those who completed up to the fourth follow-up were included in the study. Ethical approval of the KOBIO registry was obtained from the institutional review boards of all 38 participating institutions, including the Institutional Review Board of Inje University Seoul Paik Hospital (PAIK 2018-11-005).

\section{Trajectory-based clustering model}

Group-based trajectory modeling (GBTM) is a model for clustering sequential data and has often been used in clinical studies [18]. The purpose of GBTM is to find groups with different characteristics by clustering response patterns over time and to compare the clustered groups. The model assumes that the dependent variable follows a certain probability distribution such as normal distribution or Poisson distribution, and that the mean of the probability distribution takes the form of polynomials over time. Under the above assumptions, parameters and functional forms are fitted by the data using maximum likelihood estimation. In our study, the sequential treatment records using biologics were clustered by response pathway based on the model and the probability distribution and parameters were determined by the medical rationale and data explanatory power. The probability of distribution of the dependent variable was chosen as the censored normal distribution. The number of clusters and the order of polynomials were determined to maximize the value of the model selection criterion, Bayesian Information Criterion, by performing several combinations. After clustering, we showed the individual response patterns to confirm the empirical results.

\section{Statistical analysis}

All data are shown as mean (standard deviation [SD]) or percentage values. For comparison of baseline characteristics and switching bDMARDs among groups, the chi-squared and Kruskal-Wallis tests were used. The odds ratio (OR) with confidence interval $(\mathrm{Cl})$ was calculated to identify the association between variables and each trajectory group. In multivariable analysis, significant variables with $p$ values $<0.1$ in univariate analysis were selected, while variables with high correlation such erythrocyte sedimentation rate (ESR) and disease activity score with 28-joint assessment (DAS28) were excluded . Statistical analyses were performed using R software version 3.6.1 (R Foundation for Statistical Computing, Vienna, Austria).

\section{Results}

\section{Patient selection and grouping according to disease trajectory}

Figure 1 shows the flow chart of patient selection. Among the patients treated with tsDMARDs, only those treated with tofacitinib were included. Of the 2122 patients, we excluded 353 patients treated with bDMARDs or tsDMARDs prior to registration in the KOBIO registry, 66 patients with missing data, and 1015 patients who did not complete the $4^{\text {th }}$ follow-up. Finally, 688 patients were included in this study. 
The 688 study patients were divided into 4 groups according to the trajectory of DAS28 (Figure $2 A)$. In group $1(n=319)$, the disease activity rapidly decreased and remained below moderate disease activity; in group $2(n=36)$, the disease activity rapidly decreased but then increased; in group $3(n=290)$, the disease activity showed a continuous but slow decrease; and in group 4 $(n=43)$, the disease activity remained high. The trajectories of each individual patient are shown in Figure $2 B$. The baseline characteristics, including the number of current smokers, BUN, cholesterol, and initial DAS28, differed significantly among the groups (table 1).

\section{Prescription patterns of bDMARDs and tsDMARDs according to trajectory groups.}

Table 2 shows the prescription patterns of bDMARDs and tsDMARDs according to trajectory groups. The proportion of patients who maintained their first prescribed bDMARDs or tsDMARDs during the follow-up period (never switching) in group 1 was $86.5 \%$, which was higher than those in groups 2,3 , and 4 ( $52.8 \%, 50.3 \%$, and $25.6 \%$, respectively). The mean number of bDMARDs or tsDMARDs prescribed was higher in group 4 (2.3) than in groups 1 (1.1), 2 (1.7), and 3 (1.6), albeit without statistical significance $(p=0.652)$. The proportion of patients who were prescribed non-tumor necrosis factor (TNF) inhibitor as initial treatment was higher in group $1(44.2 \%)$ than in groups 2,3 , and $4(30.5 \%, 23.4 \%$, and $18.6 \%$, respectively).

\section{Predictive factors for disease trajectory}

The odds ratio of comparisons between group 1 (ie, good treatment response) and groups 2, 3, and 4 were calculated with a univariate model (table 3). Compared with group 1, group 2 was associated with ESR (OR, 1.018; 95\% Cl, 1.005-1.031), group 3 was associated with cholesterol (OR, 1.009; 95\% Cl, 1.004-1.015), ESR (OR, 1.020; 95\% Cl, 1.013-1.027), and initial DAS28 (OR, $1.884 ; 95 \% \mathrm{Cl}, 1.556-2.302)$ and less associated with BUN (OR, 0.958; 95\% Cl, 0.922-0.993), and group 4 was associated with current smoking (OR, 4.773; 95\% Cl, 1.556-13.452), lower hemoglobin (OR, 1.020; 95\% Cl, 1.007-1.032), higher ESR (OR, 0.745; $95 \% \mathrm{Cl}, 0.586-0.941)$, and initial DAS28 (OR, 2.522; 95\% Cl, 1.738-3.732).

Multivariable analysis (table 4) showed that compared with group 1, group 2 was associated with ESR (OR, 1.018; 95\% Cl, 1.005-1.031), group 3 was associated with $\mathrm{BMI}(\mathrm{OR}, 1.055$; $95 \% \mathrm{Cl}, 1.001-1.115)$, current smoking (OR, 2.554; $95 \% \mathrm{Cl}, 1.093-$ 6.271), cholesterol (OR, 1.011; 95\% Cl, 1.004-1.017), and initial DAS28 (OR, 1.828; 95\% Cl: 1.500-2.249), and negatively associated with hemoglobin (OR, 0.818; $95 \% \mathrm{Cl}, 0.715-0.932)$ and $\mathrm{BUN}(\mathrm{OR}, 0.946 ; 95 \% \mathrm{Cl}, 0.908-0.984)$, and group 4 was associated with current smoking (OR, 7.845; 95\% Cl, 2.158-28.220), low hemoglobin (OR, 0.694; 95\% Cl, 0.532-0.901), and initial DAS28 (OR, 2.397; 95\% Cl, 1.638-3.586).

\section{Discussion}

In this study, we clustered the trajectories of the disease activity of RA patients during 4 years of treatment with bDMARDs or tsDMARDs into 4 patterns. From those trajectories, we found several distinguishing baseline features of 3 trajectories compared with the trajectory with good treatment response (ie, group 1 with a rapid decrease in disease activity without subsequent increases). Among the baseline features, current smoking, low hemoglobin, and high initial DAS28 were associated with persistently high disease activity in patients with RA treated with bDMARDs or tsDMARDs. In addition, patients who maintained a good response had less switching of bDMARDs or tsDMARDs and a higher rate of using non-TNF inhibitor as initial treatment.

Various trajectory studies have been conducted on RA patients. A study using the Swedish BARFOT cohort identified three trajectories: best (39.6\%), moderate (41.5\%), and worst (18.9\%) outcomes [13]. Trajectories using Australia's cohort were similarly divided into good (43.8\%), moderate (39.7\%), and poor (16.5\%) outcome groups and there was a significant difference in BMI and the proportion of ever smokers between the poor outcomes group and the good outcomes group. [16]. A study using the CATCH cohort in Canada divided the cohort into 5 trajectories, which were similar to those of the BARFOT cohort [12]. The strength of our study is that the treatment responses for bDMARDs or tsDMARDs were clustered into 4 trajectories from a 4-year longitudinal cohort data, which is a relatively long period compared with those of other studies. Moreover, we investigated the switching patterns of bDMARDs or tsDMARDs associated with each trajectory. 
In our study, group 4 (ie, disease activity remaining high for 4 years) was associated with baseline factors such as current smoking, low hemoglobin, and high initial DAS28. In RA patients, cigarette smoking is related to poor prognosis as well as treatment response [19-22], and hemoglobin is related to disease activity [23, 24]. Whereas patients in group 3 slowly improved their disease activity over 4 years, they were associated with higher BMI, current smoking, lower hemoglobin and BUN, and higher cholesterol and initial DAS28 compared with group 1. Although those factors were reported to be related to poor treatment response of RA in previous studies [21, 23-25], patients with group 3 may achieve remission slowly compared with group 1.

The trajectory that we found interesting was group 2, which was not seen in previous studies with short follow-up durations [1315]. Initially, patients in group 2 followed a similar trajectory to group 1, but there seems to have been a secondary failure of treatment to bDMARDs or tsDMARDs after a good response. In line with the fact that group 2 initially had a similar trajectory to group 1, ESR was the only predicting factor compared to group 1. Taken together, we found several predictors that were related to the differences between trajectories; however, we assume that more factors would have contributed to the difference among groups. Further studies are needed to identify individual factors that are predictive of the trends in treatment response and the optimal treatment drug for each individual.

In terms of the switching pattern of bDMARDs or tsDMARDs, as much as $86.5 \%$ of patients in group 1 maintained the initially prescribed drug without switching. Moreover, patients in group 1 responded more quickly to treatment with bDMARDs or tsDMARDs than those in other groups, and their disease activity remained low for nearly 4 years. Interestingly, patients in group 1 were more commonly prescribed non-TNF inhibitors as an initial treatment than in those in other groups. In groups 3 and 4 , $50.3 \%$ and $25.6 \%$ of patients maintained one bDMARDs or tsDMARDs, respectively, and $10.0 \%$ and $41.9 \%$ of patients switched among the DMARDs twice or more, respectively. Differences in trajectories, such as delayed or poor treatment response despite frequent drug replacement, suggest the need for personalized drug selection for each RA patient [26-28]. Moreover, considering the multifactorial characteristics of RA, new drugs countering the various mechanisms of RA must be developed [29, 30].

There were some limitations to our study. First, changes in disease activity related to the type and dosage of DMARDs and individual adherence were not considered in this study. Therefore, it may be difficult to generalize the results of this study to individual patients. Second, a small number of tsDMARD users were included in this study, which also limits the generalizability of the results of this study. Third, if we had included more patients or analyzed longer follow-up durations, we may have discovered more than 4 trajectries in various situations.

In conclusion, we were able to cluster the trend of disease activity over 4 years in patients treated with bDMARDs or tsDMARDs into 4 distinct trajectories, and found that baseline characteristics such as current smoking, low hemoglobin, and high initial DAS28 may be associated with poor prognosis and sustained high disease activity. Our study suggests that the trajectory-based clustering approach for disease activity may be useful in predicting treatment responses from longitudinal data in real-world practice and making decisions about treatment plans in patients with RA.

\section{Abbreviations}

ACPA, anti-cyclic citrullinated peptide antibody

ALT, alanine aminotransferase

ANA, anti-nuclear antibody

AST, aspartate aminotransferase

bDMARDs, biologic disease-modifying anti-rheumatic drugs

BUN, blood urea nitrogen

$\mathrm{Cl}$, confidence interval

CRP, C-reactive protein

Page 5/13 
DAS28, disease activity score with 28-joint assessment

DAS28-ESR, disease activity scores in 28 joints using the erythrocyte sedimentation rate

DMARDs (disease-modifying anti-rheumatic drugs)

ESR, erythrocyte sedimentation rate

GBTM, Group-based trajectory modeling

KOBIO, Korean College of Rheumatology Biologics \& Targeted therapy Registry

LB, lowe bound

OR, odds ratio

RA, rheumatoid arthritis

$\mathrm{RF}$, rheumatoid factor

SD, standard deviation

TNF, tumor necrosis factor

tsDMARDs, targeted synthetic disease-modifying anti-rheumatic drugs

UB, upper bound

\section{Declarations}

Ethics approval and consent to participate: Ethical approval of the KOBIO registry was obtained from the institutional review boards of all 38 participating institutions, including the Institutional Review Board of Inje University Seoul Paik Hospital (PAIK 2018-11-005).

Consent for publication: not applicable.

Author contributions: Dr. Oh had full access to all of the data used in the study and takes responsibility for the integrity of the data, study supervision, and accuracy of its analysis.

Concept and design: Koo, Eun, and Oh.

Acquisition, analysis, or interpretation of data: All authors.

Drafting of the manuscript. Koo, Eun, and Oh.

Critical revision of the manuscript for important intellectual content. All authors.

Statistical analysis: Koo, Eun, and Oh.

Obtained funding: Koo and Oh.

Administrative, technical, or material support: Koo, Eun, and Oh.

Supervision: Hong, Kim, Lee, Yoo, and Oh.

Acknowledgement: The registry was funded by the Korean College of Rheumatology, which had no involvement in the study design, collection, analysis, and interpretation of the data; in writing the manuscript; or in the decision to submit the manuscript 
for publication. We would like to thank all members of the Korean College of Rheumatology Biology (KOBIO) registry. We thank Dr. Joon Seo Lim from the Scientific Publications Team at Asan Medical Center for his editorial assistance in preparing this manuscript.

Availability of data and material: Data are available from the Clinical Research Committee of KOBIO under the Korean College of Rheumatology for researchers who meet the criteria for access to confidential data. To request data, please contact Kichul Shin, MD, PhD, Director of the Korean College of Rheumatology Biologics Registry, Associate Professor of the Division of Rheumatology, Director of Logistics Planning at SMG-SNU, Boramae Medical Center, 20 Boramae-ro-5-gil, Dongjak-gu, Seoul, 07061, Korea; Tel: +82-2-870-3204; Fax: +82-2-870-3866; Email: rk.ca.uns@1bedik.

Competing interests: The authors declare that they have no competing interests.

Funding: This work was supported by the following grants: the National Research Foundation of Korea (NRF) grant funded by the Korean government (MSIT). (No. NRF-2021R1C1C1009815); a grant (2021IP0047) from the Asan Institute for Life Sciences, Asan Medical Center, Seoul, Korea; The Technology Innovation Program (20004927, Upgrade of CDM based Distributed Biohealth Data Platform and Development of Verification Technology) funded by the Ministry of Trade, Industry \& Energy (MOTIE, Korea); the Korea Health Technology R\&D Project through the Korea Health Industry Development Institute (KHIDI), funded by the Ministry of Health \& Welfare, Republic of Korea (HR21C0198).

\section{References}

1. Grigor C, Capell H, Stirling A, McMahon AD, Lock P, Vallance R, Kincaid W, Porter D: Effect of a treatment strategy of tight control for rheumatoid arthritis (the TICORA study): a single-blind randomised controlled trial. Lancet 2004, 364(9430):263269.

2. Kavanaugh A, van Vollenhoven RF, Fleischmann R, Emery P, Sainsbury I, Florentinus S, Chen S, Guerette B, Kupper H, Smolen JS: Testing treat-to-target outcomes with initial methotrexate monotherapy compared with initial tumour necrosis factor inhibitor (adalimumab) plus methotrexate in early rheumatoid arthritis. Ann Rheum Dis 2018, 77(2):289-292.

3. Lau CS, Chia F, Dans L, Harrison A, Hsieh TY, Jain R, Jung SM, Kishimoto M, Kumar A, Leong KP et al: 2018 update of the APLAR recommendations for treatment of rheumatoid arthritis. Int $J$ Rheum Dis 2019, 22(3):357-375.

4. Singh JA, Saag KG, Bridges SL, Jr., AkI EA, Bannuru RR, Sullivan MC, Vaysbrot E, McNaughton C, Osani M, Shmerling RH et al: 2015 American College of Rheumatology Guideline for the Treatment of Rheumatoid Arthritis. Arthritis Rheumatol 2016, 68(1):1-26.

5. Smolen JS, Landewe RBM, Bijlsma JWJ, Burmester GR, Dougados M, Kerschbaumer A, Mclnnes IB, Sepriano A, van Vollenhoven RF, de Wit M et al: EULAR recommendations for the management of rheumatoid arthritis with synthetic and biological disease-modifying antirheumatic drugs: 2019 update. Ann Rheum Dis 2020, 79(6):685-699.

6. Grabner M, Boytsov NN, Huang Q, Zhang X, Yan T, Curtis JR: Costs associated with failure to respond to treatment among patients with rheumatoid arthritis initiating TNFi therapy: a retrospective claims analysis. Arthritis Res Ther 2017, 19(1):92.

7. Navarro F, Martinez-Sesmero JM, Balsa A, Peral C, Montoro M, Valderrama M, Gomez S, de Andres-Nogales F, Casado MA, Oyaguez I: Cost-effectiveness analysis of treatment sequences containing tofacitinib for the treatment of rheumatoid arthritis in Spain. Clin Rheumatol 2020, 39(10):2919-2930.

8. Lequerre T, Rottenberg P, Derambure C, Cosette P, Vittecoq O: Predictors of treatment response in rheumatoid arthritis. Joint Bone Spine 2019, 86(2):151-158.

9. Cuppen BV, Welsing PM, Sprengers JJ, Bijlsma JW, Marijnissen AC, van Laar JM, Lafeber FP, Nair SC: Personalized biological treatment for rheumatoid arthritis: a systematic review with a focus on clinical applicability. Rheumatology (Oxford) 2016, 55(5):826-839.

10. Katchamart W, Johnson S, Lin HJ, Phumethum V, Salliot C, Bombardier C: Predictors for remission in rheumatoid arthritis patients: A systematic review. Arthritis Care Res (Hoboken) 2010, 62(8):1128-1143. 
11. Wijbrandts CA, Tak PP: Prediction of Response to Targeted Treatment in Rheumatoid Arthritis. Mayo Clin Proc 2017, 92(7):1129-1143.

12. Barnabe C, Sun Y, Boire G, Hitchon CA, Haraoui B, Thorne JC, Tin D, van der Heijde D, Curtis JR, Jamal S et al: Heterogeneous Disease Trajectories Explain Variable Radiographic, Function and Quality of Life Outcomes in the Canadian Early Arthritis Cohort (CATCH). PLoS One 2015, 10(8):e0135327.

13. Leu Agelii M, Andersson M, Jones BL, Sjowall C, Kastbom A, Hafstrom I, Forslind K, Gjertsson I: Disease activity trajectories in rheumatoid arthritis: a tool for prediction of outcome. Scand J Rheumato/ 2021, 50(1):1-10.

14. Norton S, Sacker A, Dixey J, Done J, Williams P, Young A, Early Rheumatoid Arthritis S: Trajectories of functional limitation in early rheumatoid arthritis and their association with mortality. Rheumatology (Oxford) 2013, 52(11):2016-2024.

15. Siemons L, Ten Klooster PM, Vonkeman HE, Glas CA, Van de Laar M: Distinct trajectories of disease activity over the first year in early rheumatoid arthritis patients following a treat-to-target strategy. Arthritis Care Res (Hoboken) 2014, 66(4):625630.

16. Wabe N, Wojciechowski J, Wechalekar MD, Cleland LG, McWilliams L, Lee A, Proudman S, Wiese MD: Disease activity trajectories in early rheumatoid arthritis following intensive DMARD therapy over 3 years: association with persistence to therapy. Int J Rheum Dis 2017, 20(10):1447-1456.

17. Shin K, Choi SJ, Kwak S-K, Park Y-B, Sung Y-K, Choi C-B, Jeon CH, Lee J, Nam EJ, Kim S-K et al: AB1066 Korean Biologics Registry of Patients with Systemic Rheumatic Disease (KOBIO): A Nationwide Registry to Assess Adverse Events Associated with Biologic Treatment in Korea. Annals of the Rheumatic Diseases 2014, 73:1153-1154.

18. Nagin DS, Odgers CL: Group-based trajectory modeling in clinical research. Annu Rev Clin Psychol 2010, 6:109-138.

19. Gianfrancesco MA, Trupin L, Shiboski S, van der Laan M, Graf J, Imboden J, Yazdany J, Schmajuk G: Smoking Is Associated with Higher Disease Activity in Rheumatoid Arthritis: A Longitudinal Study Controlling for Time-varying Covariates. $J$ Rheumatol 2019, 46(4):370-375.

20. Hamann PDH, Pauling JD, McHugh N, Shaddick G, Hyrich K, Group B-RC: Predictors, demographics and frequency of sustained remission and low disease activity in anti-tumour necrosis factor-treated rheumatoid arthritis patients. Rheumatology (Oxford) 2019, 58(12):2162-2169.

21. Rydell E, Forslind K, Nilsson JA, Jacobsson LTH, Turesson C: Smoking, body mass index, disease activity, and the risk of rapid radiographic progression in patients with early heumatoid arthritis. Arthritis Res Ther 2018, 20(1):82.

22. Soderlin MK, Petersson IF, Geborek P: The effect of smoking on response and drug survival in rheumatoid arthritis patients treated with their first anti-TNF drug. Scand J Rheumato/ 2012, 41(1):1-9.

23. Moller B, Scherer A, Forger F, Villiger PM, Finckh A, Swiss Clinical Quality Management Program for Rheumatic D: Anaemia may add information to standardised disease activity assessment to predict radiographic damage in rheumatoid arthritis: a prospective cohort study. Ann Rheum Dis 2014, 73(4):691-696.

24. Wilson A, Yu HT, Goodnough LT, Nissenson AR: Prevalence and outcomes of anemia in rheumatoid arthritis: a systematic review of the literature. Am J Med 2004, 116 Suppl 7A:50S-57S.

25. Park YJ, Cho CS, Emery P, Kim WU: LDL cholesterolemia as a novel risk factor for radiographic progression of rheumatoid arthritis: a single-center prospective study. PLoS One 2013, 8(7):e68975.

26. Isaacs JD, Ferraccioli G: The need for personalised medicine for rheumatoid arthritis. Annals of the Rheumatic Diseases 2011, 70(1):4.

27. Tak PP: A personalized medicine approach to biologic treatment of rheumatoid arthritis: a preliminary treatment algorithm. Rheumatology (Oxford) 2012, 51(4):600-609.

28. Koo BS, Eun S, Shin K, Yoon H, Hong C, Kim D-H, Hong S, Kim Y-G, Lee C-K, Yoo B et al: Machine learning model for identifying important clinical features for predicting remission in patients with rheumatoid arthritis treated with biologics. Arthritis Research \& Therapy 2021, 23(1):178.

29. Chaudhari K, Rizvi S, Syed BA: Rheumatoid arthritis: current and future trends. Nature Reviews Drug Discovery 2016, 15(5):305-306. 
30. Shams S, Martinez JM, Dawson JRD, Flores J, Gabriel M, Garcia G, Guevara A, Murray K, Pacifici N, Vargas MV et al: The Therapeutic Landscape of Rheumatoid Arthritis: Current State and Future Directions. Frontiers in Pharmacology 2021, 12(1233).

\section{Tables}

Table 1. Baseline characteristics of patients according to trajectory-based clustering.

\begin{tabular}{|c|c|c|c|c|c|c|}
\hline & $\begin{array}{l}\text { Total } \\
(\mathrm{N}=688)\end{array}$ & $\begin{array}{l}\text { Group } 1 \\
(\mathrm{~N}=319)\end{array}$ & $\begin{array}{l}\text { Group } 2 \\
(\mathrm{~N}=36)\end{array}$ & $\begin{array}{l}\text { Group } 3 \\
(\mathrm{~N}=290)\end{array}$ & $\begin{array}{l}\text { Group } 4 \\
(\mathrm{~N}=43)\end{array}$ & $p$ \\
\hline Age, year & $52.9(12.2)$ & $52.0(12.3)$ & $53.6(13.2)$ & $53.6(12.1)$ & $54.4(11.1)$ & 0.729 \\
\hline Male sex, n (\%) & $97(14.1)$ & $46(14.4)$ & $7(19.4)$ & $35(12.1)$ & 9 (20.9) & 0.318 \\
\hline Body mass index, $\mathrm{kg} / \mathrm{m}^{2}$ & $22.4(3.4)$ & $22.2(2.9)$ & $22.5(2.7)$ & $22.7(3.8)$ & $22.4(4.2)$ & 0.290 \\
\hline Symptom duration, year & $7.2(7.1)$ & $7.1(7.2)$ & $8.3(8.4)$ & $7.2(6.9)$ & $7.6(7.5)$ & 0.476 \\
\hline \multicolumn{7}{|l|}{ Smoking, n (\%) } \\
\hline Current smoker & $38(5.5)$ & $11(3.4)$ & $1(2.8)$ & $20(6.9)$ & $6(14.0)$ & 0.018 \\
\hline Ex-smoker & $55(8.0)$ & $28(8.8)$ & $3(8.3)$ & $19(6.6)$ & $5(11.6)$ & 0.601 \\
\hline Never smoker & $595(86.5)$ & $280(87.8)$ & $32(88.9)$ & $251(86.6)$ & $32(74.4)$ & 0.112 \\
\hline Prednisolone dose, mg & $5.1(3.7)$ & $4.9(3.7)$ & $5.9(6.4)$ & $5.1(3.2)$ & $5.2(3.6)$ & 0.545 \\
\hline Methotrexate dose, mg & $10.5(5.6)$ & $10.6(5.3)$ & $11.3(4.9)$ & $10.3(5.8)$ & $9.3(6.7)$ & 0.714 \\
\hline Hemoglobin, g/dL & $12.0(1.4)$ & $12.2(1.3)$ & $12.0(1.1)$ & $11.9(1.4)$ & $11.6(1.5)$ & 0.354 \\
\hline ALT, IU/L & $19.2(12.5)$ & $19.2(11.6)$ & $20.1(12.4)$ & $19.0(12.3)$ & $20.0(18.5)$ & 0.557 \\
\hline AST, IU/L & $21.2(9.8)$ & $20.9(7.1)$ & $21.6(6.9)$ & $21.3(9.0)$ & $23.5(24.1)$ & 0.588 \\
\hline BUN, mg/dL & $14.2(4.5)$ & $14.5(4.5)$ & $14.0(4.3)$ & $13.7(4.2)$ & $15.6(5.9)$ & 0.041 \\
\hline Creatinine, $\mathrm{mg} / \mathrm{dL}$ & $0.7(0.2)$ & $0.7(0.2)$ & $0.7(0.2)$ & $0.7(0.3)$ & $0.7(0.3)$ & 0.724 \\
\hline Cholesterol, mg/dL & $174.3(27.7)$ & $171.4(27.0)$ & $171.1(22.0)$ & $178.6(28.7)$ & $169.0(26.5)$ & 0.003 \\
\hline $\mathrm{ESR}, \mathrm{mm} / \mathrm{hr}$ & $49.2(25.4)$ & $43.0(22.9)$ & $54.6(31.7)$ & $54.5(25.2)$ & $55.6(28.8)$ & 0.103 \\
\hline $\mathrm{CRP}, \mathrm{mg} / \mathrm{dL}$ & $2.2(2.8)$ & $2.1(2.4)$ & $2.7(2.8)$ & $2.4(3.2)$ & $2.0(2.1)$ & 0.792 \\
\hline ANA positivity, $\mathrm{n}(\%)$ & 247 (35.9) & $116(36.4)$ & $13(36.1)$ & $104(35.9)$ & $14(32.6)$ & 0.971 \\
\hline RF positivity, n (\%) & $595(86.5)$ & $275(86.2)$ & $32(88.9)$ & $255(87.9)$ & $33(76.7)$ & 0.240 \\
\hline ACPA positivity, n (\%) & $515(74.9)$ & $238(74.6)$ & $27(75.0)$ & $220(75.9)$ & $30(69.8)$ & 0.859 \\
\hline Initial DAS28 & $5.68(0.95)$ & $5.4(0.9)$ & $5.5(1.2)$ & $5.9(0.9)$ & $6.1(1.0)$ & 0.002 \\
\hline
\end{tabular}

*Glucocorticoid dose (eg, prednisolone, methylprednisolone, deflazacort, and dexamethasone) was converted to prednisolone doses.

Data are mean (standard deviation) unless noted otherwise.

ACPA, anti-cyclic citrullinated peptide antibody; ALT, alanine aminotransferase; ANA, anti-nuclear antibody; AST, aspartate aminotransferase; BUN, blood urea nitrogen; CRP, C-reactive protein; DAS28-ESR, disease activity scores in 28 joints using the erythrocyte sedimentation rate; ESR, erythrocyte sedimentation rate; RF, rheumatoid factor. 
Table 2. Switching pattern of bDMARDs or tsDMARDs in each trajectory group.

\begin{tabular}{|c|c|c|c|c|c|}
\hline & $\begin{array}{l}\text { Group } 1 \\
(\mathrm{~N}=319)\end{array}$ & $\begin{array}{l}\text { Group } 2 \\
(\mathrm{~N}=36)\end{array}$ & $\begin{array}{l}\text { Group } 3 \\
(\mathrm{~N}=290)\end{array}$ & $\begin{array}{l}\text { Group } 4 \\
(\mathrm{~N}=43)\end{array}$ & $p$ \\
\hline Number of switches for bDMARDs or tsDMARDs, $\mathrm{n}(\%)$ & & & & & $<0.001$ \\
\hline Never & $276(86.5)$ & $19(52.8)$ & $146(50.3)$ & $11(25.6)$ & \\
\hline Once & $40(12.5)$ & $11(30.6)$ & $115(39.7)$ & $14(32.6)$ & \\
\hline Twice & $3(0.9)$ & $5(13.9)$ & $26(9.0)$ & $11(25.6)$ & \\
\hline Three times & $0(0.0)$ & $1(2.8)$ & $2(0.7)$ & $6(14.0)$ & \\
\hline Four times & $0(0.0)$ & $0(0.0)$ & $1(0.3)$ & $1(2.3)$ & \\
\hline Number of bDMARDs or tsDMARDs, mean (SD) & $1.1(0.4)$ & $1.7(0.8)$ & $1.6(0.7)$ & $2.3(1.1)$ & 0.652 \\
\hline Number of TNF inhibitors, mean (SD) & $0.6(0.5)$ & $1.0(0.8)$ & $0.9(0.6)$ & $1.2(0.7)$ & 0.847 \\
\hline Number of non-TNF inhibitors, mean (SD) & $0.6(0.6)$ & $0.7(0.6)$ & $0.7(0.7)$ & $1.2(1.0)$ & 0.524 \\
\hline Initial bDMARDs or tsDMARDs, n (\%) & & & & & $<0.001$ \\
\hline Adalimumab & $56(17.6)$ & $11(30.6)$ & $76(26.2)$ & $8(18.6)$ & \\
\hline Etanercept & $60(18.8)$ & $7(19.4)$ & $57(19.7)$ & $14(32.6)$ & \\
\hline Golimumab & $21(6.6)$ & $1(2.8)$ & $28(9.7)$ & $3(7.0)$ & \\
\hline Infliximab & $41(12.9)$ & $6(16.7)$ & $61(21.0)$ & $10(23.3)$ & \\
\hline Abatacept & $47(14.7)$ & $3(8.3)$ & $39(13.4)$ & $1(2.3)$ & \\
\hline Rituximab & $0(0.0)$ & $0(0.0)$ & $1(0.3)$ & $0(0.0)$ & \\
\hline Tocilizumab & $93(29.2)$ & $8(22.2)$ & $28(9.7)$ & $6(14.0)$ & \\
\hline Tofacitinib & $1(0.3)$ & $0(0.0)$ & $0(0.0)$ & $1(2.3)$ & \\
\hline Initial TNF inhibitor or non-TNF inhibitor, n (\%) & & & & & $<0.001$ \\
\hline TNF inhibitor & $178(55.8)$ & $27(75)$ & $222(76.6)$ & $35(81.4)$ & \\
\hline Non-TNF inhibitor & $141(44.2)$ & $11(30.5)$ & $68(23.4)$ & $8(18.6)$ & \\
\hline
\end{tabular}

bDMARDs, biologic disease-modifying anti-rheumatic drugs; TNF, tumor necrosis factor; SD, standard deviation; tsDMARDs, targeted synthetic disease-modifying anti-rheumatic drugs.

Table 3. Odds ratios of predictive factors for each trajectory group in univariate analysis. 


\begin{tabular}{|c|c|c|c|c|c|c|c|c|c|c|c|c|}
\hline & \multicolumn{4}{|c|}{ Group 1 vs. Group 2} & \multicolumn{4}{|c|}{ Group 1 vs. Group 3} & \multicolumn{4}{|c|}{ Group 1 vs. Group 4} \\
\hline & OR & LB & UB & $p$ & OR & LB & UB & $p$ & OR & LB & UB & $p$ \\
\hline Age & 1.011 & 0.983 & 1.041 & 0.453 & 1.011 & 0.998 & 1.024 & 0.102 & 1.017 & 0.990 & 1.046 & 0.223 \\
\hline Male sex & 1.433 & 0.551 & 3.300 & 0.425 & 0.815 & 0.506 & 1.302 & 0.394 & 1.571 & 0.671 & 3.371 & 0.267 \\
\hline $\begin{array}{l}\text { Body mass } \\
\text { index }\end{array}$ & 1.034 & 0.917 & 1.163 & 0.580 & 1.047 & 0.998 & 1.099 & 0.062 & 1.025 & 0.924 & 1.132 & 0.631 \\
\hline $\begin{array}{l}\text { Symptom } \\
\text { duration }\end{array}$ & 1.021 & 0.974 & 1.065 & 0.365 & 1.001 & 0.979 & 1.024 & 0.902 & 1.009 & 0.965 & 1.051 & 0.677 \\
\hline $\begin{array}{l}\text { Current } \\
\text { smoking (ref: } \\
\text { never) }\end{array}$ & 0.795 & 0.043 & 4.295 & 0.829 & 2.028 & 0.970 & 4.462 & 0.067 & 4.773 & 1.556 & 13.452 & 0.004 \\
\hline $\begin{array}{l}\text { Ex-smoking } \\
\text { (ref: never) }\end{array}$ & 0.938 & 0.216 & 2.843 & 0.919 & 0.757 & 0.407 & 1.380 & 0.369 & 1.562 & 0.504 & 4.032 & 0.391 \\
\hline $\begin{array}{l}\text { Prednisolone } \\
\text { dose }\end{array}$ & 1.052 & 0.973 & 1.128 & 0.170 & 1.020 & 0.974 & 1.069 & 0.399 & 1.023 & 0.936 & 1.105 & 0.589 \\
\hline $\begin{array}{l}\text { Methotrexate } \\
\text { dose }\end{array}$ & 1.028 & 0.961 & 1.107 & 0.444 & 0.991 & 0.963 & 1.020 & 0.542 & 0.958 & 0.907 & 1.013 & 0.126 \\
\hline Hemoglobin & 0.896 & 0.688 & 1.164 & 0.413 & 0.837 & 0.743 & 0.941 & 0.003 & 0.745 & 0.586 & 0.941 & 0.014 \\
\hline ALT & 1.006 & 0.976 & 1.032 & 0.650 & 0.999 & 0.986 & 1.012 & 0.888 & 1.005 & 0.979 & 1.027 & 0.670 \\
\hline AST & 1.014 & 0.965 & 1.060 & 0.557 & 1.007 & 0.987 & 1.027 & 0.507 & 1.016 & 0.991 & 1.043 & 0.169 \\
\hline BUN & 0.974 & 0.893 & 1.052 & 0.519 & 0.958 & 0.922 & 0.993 & 0.022 & 1.043 & 0.978 & 1.108 & 0.183 \\
\hline Creatinine & 0.755 & 0.074 & 6.053 & 0.802 & 1.079 & 0.500 & 2.371 & 0.840 & 3.224 & 0.763 & 13.669 & 0.094 \\
\hline Cholesterol & 1.000 & 0.986 & 1.013 & 0.945 & 1.009 & 1.004 & 1.015 & 0.002 & 0.997 & 0.985 & 1.008 & 0.579 \\
\hline ESR & 1.018 & 1.005 & 1.031 & 0.007 & 1.020 & 1.013 & 1.027 & $<0.001$ & 1.020 & 1.007 & 1.032 & 0.002 \\
\hline CRP & 1.096 & 0.966 & 1.226 & 0.122 & 1.040 & 0.981 & 1.107 & 0.199 & 0.98 & 0.835 & 1.114 & 0.779 \\
\hline $\begin{array}{l}\text { ANA } \\
\text { positivity }\end{array}$ & 0.989 & 0.471 & 2.00 & 0.976 & 0.978 & 0.702 & 1.362 & 0.898 & 0.845 & 0.418 & 1.637 & 0.626 \\
\hline RF positivity & 1.280 & 0.478 & 4.451 & 0.656 & 1.166 & 0.726 & 1.884 & 0.527 & 0.528 & 0.250 & 1.198 & 0.107 \\
\hline $\begin{array}{l}\text { ACPA } \\
\text { positivity }\end{array}$ & 1.021 & 0.477 & 2.382 & 0.959 & 1.070 & 0.740 & 1.549 & 0.720 & 0.785 & 0.398 & 1.625 & 0.498 \\
\hline Initial DAS28 & 1.119 & 0.765 & 1.660 & 0.570 & 1.884 & 1.556 & 2.302 & $\begin{array}{l}< \\
0.001\end{array}$ & 2.522 & 1.738 & 3.732 & $\begin{array}{l}< \\
0.001\end{array}$ \\
\hline
\end{tabular}

ACPA, anti-cyclic citrullinated peptide antibody; ALT, alanine aminotransferase; ANA, anti-nuclear antibody; AST, aspartate aminotransferase; BUN, blood urea nitrogen; CRP, C-reactive protein; DAS28-ESR, disease activity scores in 28 joints using the erythrocyte sedimentation rate; ESR, erythrocyte sedimentation rate; LB, lowe bound; OR, odds ratio; RF, rheumatoid factor; UB, upper bound

Table 4. Odds ratios of predictive factors for each trajectory group in multivariable analysis. 


\begin{tabular}{|c|c|c|c|c|c|c|c|c|c|c|c|c|}
\hline & \multicolumn{4}{|c|}{ Group 1 vs. Group 2} & \multicolumn{4}{|c|}{ Group 1 vs. Group 3} & \multicolumn{4}{|c|}{ Group 1 vs. Group 4} \\
\hline & OR & LB & UB & $p$ & OR & LB & UB & $p$ & OR & LB & UB & $p$ \\
\hline $\begin{array}{l}\text { Body mass } \\
\text { index }\end{array}$ & - & - & - & - & 1.055 & 1.001 & 1.115 & 0.049 & - & - & - & - \\
\hline $\begin{array}{l}\text { Current } \\
\text { smoking (ref: } \\
\text { never) }\end{array}$ & - & - & - & - & 2.554 & 1.093 & 6.271 & 0.034 & 7.845 & 2.158 & 28.220 & 0.001 \\
\hline $\begin{array}{l}\text { Ex- } \\
\text { smoking (ref: } \\
\text { never) }\end{array}$ & - & - & - & - & 0.900 & 0.465 & 1.716 & 0.751 & 1.586 & 0.473 & 4.533 & 0.416 \\
\hline Hemoglobin & - & - & - & - & 0.818 & 0.715 & 0.932 & 0.003 & 0.694 & 0.532 & 0.901 & 0.006 \\
\hline BUN & - & - & - & - & 0.946 & 0.908 & 0.984 & 0.006 & - & - & - & - \\
\hline Creatinine & - & - & - & - & - & - & - & - & 2.643 & 0.627 & 12.586 & 0.184 \\
\hline Cholesterol & - & - & - & - & 1.011 & 1.004 & 1.017 & 0.001 & - & - & - & - \\
\hline ESR & 1.018 & 1.005 & 1.031 & 0.007 & - & - & - & - & - & - & - & - \\
\hline Initial DAS28 & - & - & - & - & 1.828 & 1.500 & 2.249 & $\begin{array}{l}< \\
0.001\end{array}$ & 2.397 & 1.638 & 3.586 & $\begin{array}{l}<.001 \\
\vdots\end{array}$ \\
\hline
\end{tabular}

DAS28-ESR, disease activity scores in 28 joints using the erythrocyte sedimentation rate; ESR, erythrocyte sedimentation rate; LB, lowe bound; OR, odds ratio; UB, upper bound

Figures 


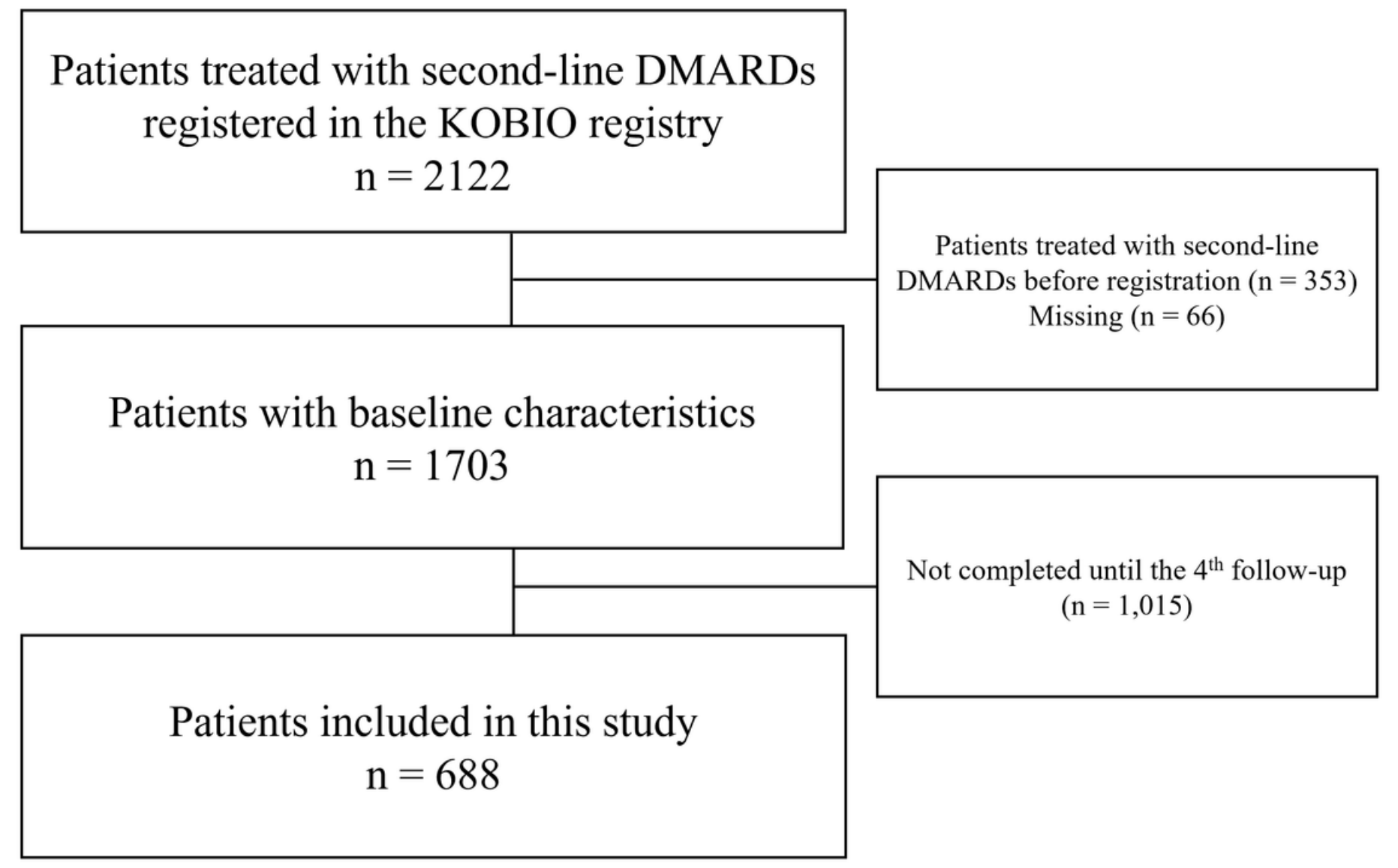

Figure 1

Flowchart of patient selection. Abbreviation: DMARDs, disease-modifying anti-rheumatic drugs.
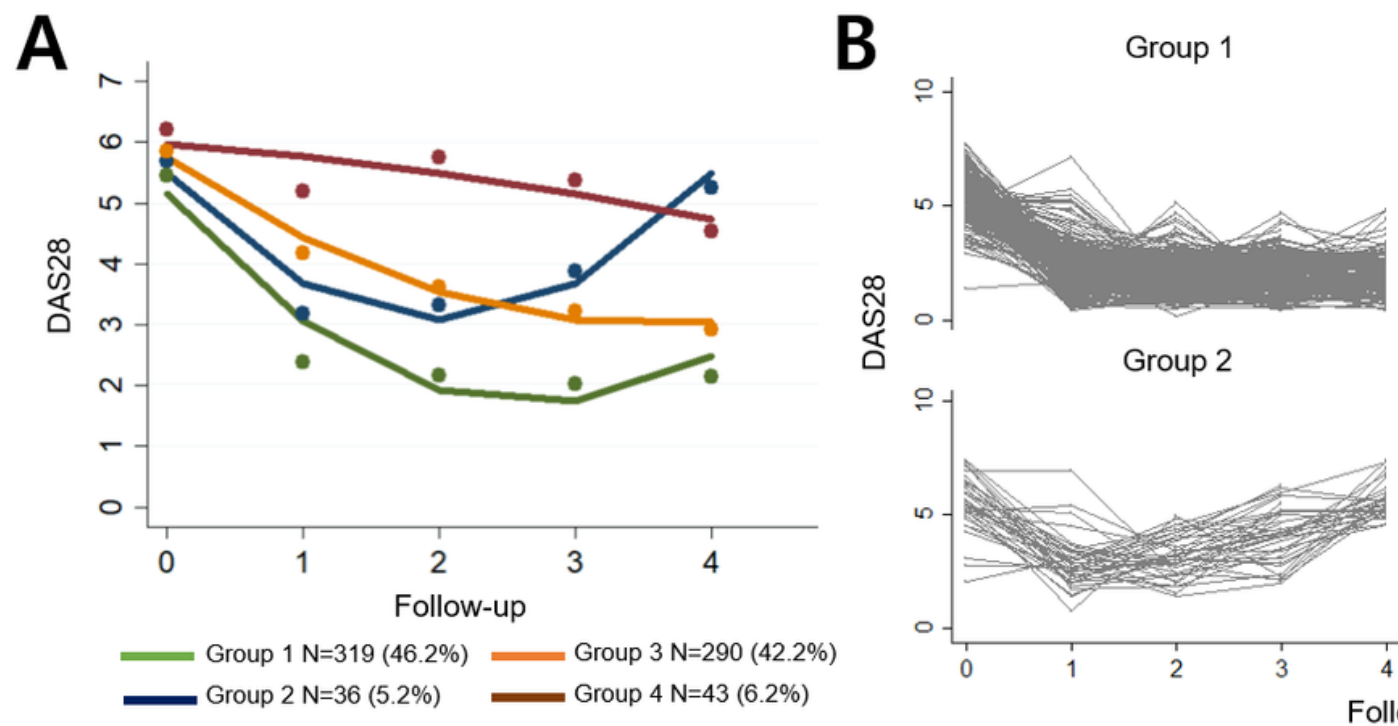

Group 3

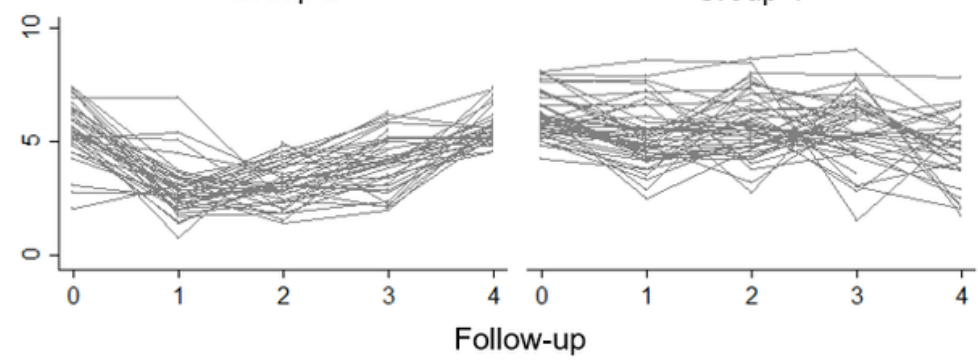

Figure 2

Trajectory-based clustering. Trajectory clustered into 4 groups (A) and changes in the disease activities of each individual over 4 years (B). Abbreviation: DAS28-ESR, disease activity scores in 28 joints using the erythrocyte sedimentation rate. 